"soma", there would be enormous financial savings on pensions, freeing capital for re-investment in the economy. Voluntary euthanasia is another alternative, but it is unlikely to find wide acceptance other than in the terminal phases of a chronic illness, for like Julius Caesar, we would probably all wish that our deaths might be unexpected.

If gradual senescence is our destiny, then economic incentives will make gerontology the pre-eminent medical specialty in developed countries. Meanwhile, nostrums that claim to prolong and improve the quality of life will continue to plague us. Gosden's book failed to anticipate the current US craze for melatonin as an anti-ageing hormone, based on the slenderest of evidence from animal stud- ies. Sadly, pseudoscientific works such as The Melatonin Miracle by Walter Pierpaoli and William Regelson and Melatonin: The Anti-Ageing Hormone by Suzanne Levert have become bestsellers in US health food stores, and the Food and Drug Administration seems unwilling, or unable, to protect the gullible American public from gross misinformation and exploitation. Gosden's first foray into popular science writing about ageing will not compete with this pulp market, but at least his scientific integrity remains intact, for he has tried to tell the truth to a wider audience. In this, he has succeeded.

Roger Short is in the Department of Obstetrics, University of Melbourne, 132 Grattan Street, Carlton, Victoria 3053, Australia.

\title{
I chat, thereby I groom
}

\section{Derek Bickerton}

Grooming, Gossip and the Evolution of Language. By Robin Dunbar. Faber: 1996. Pp. 209. £15.99, \$22.95.

EVER since we discovered we were apes, there has been pressure to explain human behaviour in terms of our primate ancestry. Surely, more of what we do is apelike than many would like to think - but is all of it? Language, arguably our best trick, offers slippery terrain for anyone committed to gradualist, unpunctuated views on evolution.

Undeterred, and armed with impressive credentials, including professorships in both psychology and biological anthropology, and field research on primates, Robin Dunbar confidently attacks the knotty issue of language origins. In breezy, insouciant prose, aiming at a nonspecialist audience, he proposes that language began not as a how-to manual for hunters but as a way of cementing alliances when our ancestors' social groups reached an unwieldy size.

Recent studies show how alliances between individuals play crucial roles in primate societies, counteracting the tyranny of alpha animals. These alliances are based on mutual grooming, but grooming takes time, up to 20 per cent in some species. As hominid groups grew, Dunbar claims, more alliances were needed, so more time was spent on grooming. At some point between 20 and 40 per cent, grooming would have interfered with other vital functions. Language would then have evolved as a grooming substitute, enabling our ancestors to establish and reinforce bonds with several individuals simultaneously.

Dunbar supports this ingenious and original proposal with cross-species correlations between brain size and group size. Primates living in larger groups have bigger brains, perhaps because they need them to keep track of more complex social networks. Statistics from several

\section{IMAGE UNAVAILABLE FOR COPYRIGHT REASONS}

sources point to an optimal human group size of around 150 individuals (three times that of any other primate), making a grooming substitute indispensable. Further support is drawn from studies showing that most conversation consists of gossip about one's own or one's acquaintances' activities - a kind of verbal grooming.

But here Dunbar commits the Fallacy of Most Frequent Use. By this reasoning, computers were invented to play video games or surf the Net, while insects grew wings in order to fly ("A cooling device? Nonsense! How often do insects use wings to cool themselves nowadays?"). In evolution, faculties often appear with one function, then get co-opted for something completely different.

Other logical flaws mar Dunbar's thesis. He assumes (with no hard evidence) that group size increased in lockstep with the brain, so one can actually pinpoint the time $(500,000$ years ago) when growing numbers forced language to emerge. But a correlation holding within the narrow range of brains below $400 \mathrm{~cm}^{3}$ does not necessarily apply when that size is quadrupled. Dunbar sees that additional motivation for group-size increase is needed. Wisely, he drops two shaky possible explanations - protection from predators, protection from members of the same species - only to adopt a third: our ancestors became nomads. But he fails to show that nomadic primates have larger groups than others, and ignores the fact that our ancestors were not, until very recently, nomads. Migration does not equal nomadism, and caves in China were inhabited continuously for countless millennia.

But language itself holds the worst pitfalls. No-one would dare to write about, say, the evolution of sex without having spent years studying all aspects of sexual reproduction. Why, apparently, can such an apprenticeship be so freely dispensed with when the topic is the evolution of language?

Blithely ignoring the many arguments against continuity between language and animal communica-

tion systems, Dunbar assumes that language developed seamlessly from primate vocalizations, which, when "a more efficient mechanism for bonding was needed... began to acquire meaning". How was this amazing feat accomplished? Dunbar seems not even to realize how amazing it was. When he gets more specific, he commits four solecisms in one sentence. New Guinea's language is not "Pison", but Tok Pisin; $\mathrm{BEV}$ is not limited to "the northeastern US"; "nation language" refers to ancestral languages of Caribbean islanders, not those they speak nowadays; and Krio, as its name suggests, is a creole not a pidgin.

The book's jacket illustration by Hayden Corner nicely captures the current landscape of language evolution studies: isolated mesas of fact separated by yawning canyons of speculation. To cross the latter requires ropes of tightly woven argument, sadly lacking here. It helps to know a bit about language, too.

Derek Bickerton is in the Department of Linguistics, University of Hawaii at Manoa, Moore Hall 569, 1890 East-West Road, Honolulu, Hawaii 96822, USA. 